\title{
SUPPLY IN MARKETING PROCESS OF ROAD TRANSPORT
}

In defining the term marketing we can come out from the sole term, which means that the term marketing is necessarily connected with market activities. These activities are arranged in a particular sequence called a marketing process. Marketing process in road transport differs in many ways from the one in the manufacturing sphere, which is determined by the fact that a road enterprise provides services. This article deals both with the issue of marketing process in road transport and position of supply in this process.

\section{Introduction}

Market factors are an essence of the market. These factors comprise elements acting in the market as a base and elements relations among them. Development of the market mechanism is determined by the existence of elements with a stabilization function. However, these elements have no sense without mutual interaction -movement and relations. It implies that market factors could be divided in the elements with stabilization function and the elements (relations) with mobilization function. Jedlička [1] named these elements stabilizers and mobilizers.

Stabilizers are the following elements:

- entrepreneur, customer, goods.

Mobilizers are the following elements:

- demand, supply.

Of course, the position and relations between the stabilizers and mobilizers are the key determinants of the whole marketing process.

In general, the supply as the mobilizer of the market expresses one direction of move, which occurs between stabilizers - entrepreneur and customer. It represents a sum of tangible and/or intangible products, which sellers are willing to offer to buyers in the market in a way that allows to satisfy both sellers ' and buyers ' needs.

The market cannot emerge and exist without the fundamental market stabilizers (entrepreneur, customer, and goods) and without two market mobilizers (demand, supply) it is not able to carry out its function. On the one hand the supply is represented by an entrepreneur and on the other hand, it effects a demand, which is represented by a customer. A dialectic essence of both supply and demand effects results in a competition function [1].

Apart from this dialectic view, a supply in road transport can also be determined as one of the basic marketing terms in road transport and also as one of the steps in the marketing process, which starts when the needs arise and ends when they are satisfied.

\section{Marketing process in road transport}

According to Kotler [2] marketing is:

“... social and regulating process through which individuals and groups gain what they need and require through creation, supply and exchange valuable goods with others".

Marketing as a term has been defined in scientific literature by many theoreticians who have developed a great deal of definitions, but the definition quoted above pertinently describes and sequences particular basic marketing terms in a way to properly characterize the chronological succession of the marketing process. See Figure 1.

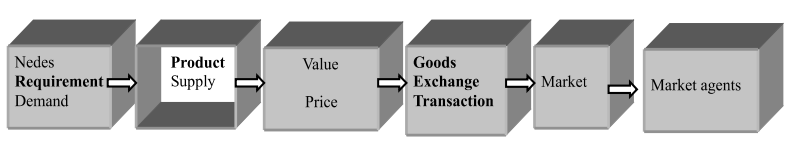

Fig. 1. Succession of marketing process

\subsection{Need, Requirement, Demand}

Need means lack of some kind of satisfaction. No firm evokes it, it is itself only in a person [2]. Neither employees of a marketing department evoke it, it has already existed before.

Requirement is a summary of the specific variants, which could meet this need. Whereas there are only a few human needs, there are a lot of requirements, which are constantly formed by the society [2].

Demand comprises lots of requirements for the specific products (goods, services) accompanied by the opportunity and willingness to buy them. So, requirements become the demand if they are supported by purchase power [2].

In case of road transport these terms get slightly different dimensions. It is rare to see needs for transport (maybe in a case of buying

\footnotetext{
* Anna Križanová,Martin Hrivnák

University of Žilina, Faculty of Operation and Economics of Transport and Communications, Economics Department, Univerzitná 1, 01026 Žilina, e-mail: anna.krizanova@fpedas,utc.sk, martin.hrivnak@fpedas.utc.sk
} 
a car, when a buyer wants to test its parameters). If transport is one of solutions to satisfy human needs (for instance, visiting friends, taking a way to work etc.) there arises requirement for transport as a means of transportation. A - sort of transport has not been specified, there is specified only the need on the level, in which transport is considered to be one of the possibilities of its satisfying. If those interested specify their requirements for transportation (specify mode of transport) and express their ability to pay for it, the requirements become the demand. While in the stage of a requirement for transportation it could be met by any mode of transport (road, railway, air transport etc.), in the stage of a demand those interested have already decided for a specific mode of transport. If they have decided for road transport they confirm their decision by buying a transport ticket or signing a freight contract. [3]

Because the marketing theory associates the demand with a concrete product, it is also necessary to do it in transport. It means to associate demand with transportation. A customer does not express his interest in transport but in a possibility of transportation. From this point of view it is effective to introduce the term demand for transportation or demand for transportation of the specific mode of transport. Application of the marketing definition (the demand is amount of goods or services, which customers are willing to buy at a specific price [2]), allows to define this marketing term from a standpoint of road transport as volumes of transportation and other services, which are customers willing to buy at a specific price. [3]

A graphical connection of these terms is shown in Fig. 2.

An assessment of requirements is several times greater in transport, for example demand for transportation in road transport. Until a customer decides for a particular transport operator, his requirement could be taken into consideration by several transport operators.

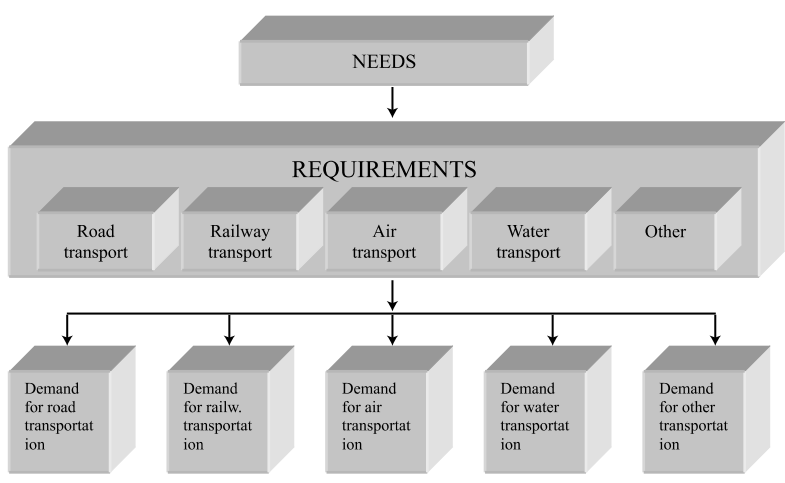

Fig. 2. Process of shiftings of needs and requirements to demand in transport

The demand is especially affected by factors lying outside a transport area. It is called a derived demand. This is the reason why the requirements for a protection of the environment are not realizable. If it were, consequently there would be decrease in the trade, freight transport and passenger transport. This is out of any transport policy power.

\subsection{Product, supply}

The next marketing term - product is obviously associated with some material - physical matter. In case of road transport this term expresses intangible goods - services, which satisfy a customer's requirements for transportation. Results of this activity are quantitatively expressed in performance of road transport firms.

Performance in road transport is determined by results of a combination of a dispositional part and real part. The term dispositional part is to be understood as a planned and organized arrangement of transportation processes, in other words, as an application of specific know-how for effectual transportation (for example, forwarding agency). The real part of the performance is a single transportation.

Other view of a road transport firm performance offers an application of the marketing theory, which divides a road transport firm performance to operational and market one. Operational performance is an offered transport performance, which becomes a market performance. Operational performance can be, for instance, and average transport distance. Market performance is, for instance, tons per kilometer and passengers per kilometer. Philosophy of inputs and outputs in a road transport firm is illustrated in Fig. 3. [3]

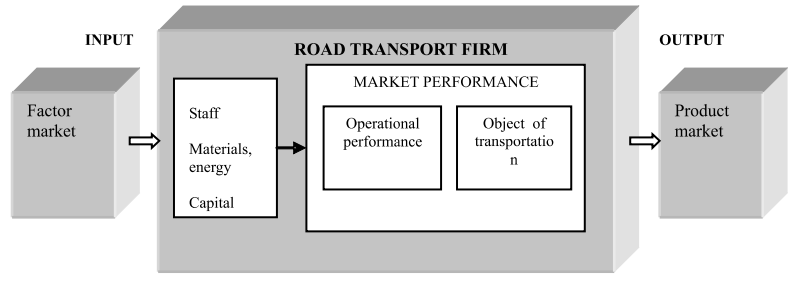

Fig. 3. Input - output of road transport firm

Volume of a market performance represents quantification of products of a road transport firm - transportation services. Supply is formed by potential transportation services, which a firm wants to offer to its customers.

The supply is another marketing term, which in road transport could be defined as a volume of transportation and other services, which road transport firms are willing to offer in the transportation market at a specific price. This definition is formulated this way for the following reasons:

1. Market price should cover seller's production costs.

2. This view on a supply allows a mathematical formulation of the supply as a function of the price.

Marketing philosophy implies that in the process of developing and forming a supply of a road transport firm emphasis must 
be put both on the requirements for transport and the demand for road transportation. A typical example is a fact that not even in the public transport firms the supply is formed without regarding actual demand for the transportation. In this case demand is source of input data for scheduling links. Demand is determined through market research or other methods. [4]

Freight transport firms or taxicabs are more responsive to a customer's requirements.

Forwarding agencies have special position in the transportation market and work between the demand and supply of the transportation as "intermediates of supply".

\subsection{Value, costs}

Marketing theory [2] explains the value of a product (goods, services) as a customer's assessment of attributes of goods or services enabling to satisfy its needs. The ratio of received benefits to invested costs determines customer's perceived value of [3]. The benefits received from a transportation service - named utility are determined by the attributes of transportation services (qualitative elements such as: speed, safety, comfort, availability and complexity of services), which should satisfy customer's needs. Invested costs of a transportation service by a customer are determined by a price for the transpiration service and all other costs associated with use of the transportation service. The value is a key criterion of choosing a product. After considering the price for transportation and assessing utilities of the available transportation services, the customer decides for a particular transportation service of a specific transport firm.

\subsection{Goods, exchange, transaction}

When people decide to satisfy their needs and requirements by a chosen product then it becomes goods, which is the object of a transaction. When exchange is carried out on the base of an agreement, then it is a transaction.

The exchange and transaction play an important role in a marketing of transport. If sellers want a transaction to be effectual, it is necessary to analyze what customers expect. Road transport firms have to analyze expectations of their customers, their requirements for transport means (speed, safety, comfort), shipping time, payment conditions and quality of additional services. If transportation services meet customer expectations, it is probable that exchange will be made and then transaction can be confirmed by an agreement.

\subsection{Market}

The terms exchange and transaction are closely connected with the term market. Marketing theory recognizes the following types of markets [2]:

- factor market and producer market,
- intermediary market,

- product market,

- government market.

Transport firms with their specific kind of services are related to all of these types of markets, because for their product - transportation and its selling they need inputs, intermediaries and customers.

The definition, which stated that the market is an area of services and circulation of goods [2], can be applied to transportation market which can be from the standpoint of a demand and supply divided in transportation market for freight transport and transportation market for passenger transport.

Both transportation markets for freight and passenger transport are not homogenous. Road transport firms offer services for various segments of customers over various geographical area. There are lots of varied criterions for a market segmentation of the transportation market, which enable to look at it from various points of view.

Simplified notions of functioning of the transportation market lead to the conclusions that the market is a sufficient instrument for development of optimal proportions within the transport system. However, foreign experiences indicate that opposite is true. For this reason the transportation market is under regulations. Incentives for regulation come from the government because transport services fulfill lots of various social and economic functions.

\subsection{Agents on the transportation market}

The producers sometimes provide their products to customers or firms without help of intermediaries. This activity is under control of the marketing department Forwarding agencies in road freight transport can be seen as marketing agents. Travel agencies play this role in passenger transport. Finally, forwarding agencies and travel agencies are customers of transport firms.

\section{Supply and supply strategy}

If a road firm has enough information on market environment, knows its internal possibilities, strengths and weaknesses, it is "qualified" to form its supply. Forming the supply of a road transport firm is necessarily determined by a supply strategy. The whole process of forming the supply should be guided by strategic decisions with the aim to develop an attractive supply. The supply strategy is to be in the focus of every firm, because it means a "playing ground".

The term strategy has its origin in Greek language, in which it means art of a leader, commander. In the past this word meant in business terminology the ability to decide with a great proficiency. Nowadays the term strategy covers a specific scheme of sequence, which outlines how set goals are to be achieved in given conditions. 
The significance of the strategy is to reach adequate effectiveness of all involved activities and to integrate all elements into one unit which provide for prospects to the given object.

Supply is an object of a supply strategy. The supply will be effective if there is a corresponding demand. There is no point to design a supply without a demand. Marketing tools can support an attractive supply.
This article is a partial outcome of the grant project: VEGA No.: 1/2567/05 Marketing activities of passenger transport enterprises in rail and road transport - participants of integrated transport system - in the process of creation and formation of a supply.

\section{References}

[1] JEDLIČKA, M.: Marketing management system, 1st. edit., MEDA Trnava, 1996, 195 p.

[2] KOTLER, Ph.: Marketing Management, $2^{\text {nd }}$ edit., Victoria Publishing, a.s.,1995, 789 p.

[3] KRIŽANOVÁ, A., BIRNEROVÁ, E.: Marketing mix in road transport, monograph, EDIS - publisher ŽU Žilina, 2002,157 p.

[4] SUROVEC, P.: Development of the system of urban passenger transport, 1st. edit., EDIS ŽU Žilina, 1999, 143 p. 